(2018). Global cancer statistics 2018: GLOBOCAN estimates of incidence and mortality worldwide for 36 cancers in 185 countries. CA: a cancer journal for clinicians, 68(6). 394-424.

2. Reid B.M., Permuth J.B., Sellers T.A. (2017). Epidemiology of ovarian cancer: a review. Cancer biology \& medicine, 14(1). 9.

3. Feig B.W., Berger D.H., Fuhrman G.M. (2006). The MD Anderson surgical oncology handbook, Lippincott Williams \& Wilkins,

4. Allemani C., Weir H.K., Carreira $H_{.}$, et al. (2015). Global surveillance of cancer survival 1995-2009: analysis of individual data for 25676 887 patients from 279 population-based registries in 67 countries (CONCORD-2). The Lancet, 385(9972). 977-1010.
5. Weber S., McCann C.K., Boruta D.M., et al. (2011). Laparoscopic surgical staging of early ovarian cancer. Reviews in Obstetrics and Gynecology, 4(3-4). 117.

6. Falcetta F.S., Lawrie T.A., Medeiros L.R., et al. (2016). Laparoscopy versus laparotomy for FIGO stage I ovarian cancer. Cochrane Database of Systematic Reviews, (10).

7. Cho JE, Liu C, Gossner G, et al (2009). Laparoscopy and gynecologic oncology. Clin Obstet Gynecol.;52:313-326

8. Nguyê̂n Trọng Diêp (2012), Nhân xét đặc điểm lâm sàng, cận lấm sàng và kêt quả điều trị ung thư buồng trứng giai đoan sớm bằng phẫu thuật kết hợp hóa chất tai bệnh viện $K$, Luận văn bác sĩ nội trú. Trường Đại học Y Hà Nội.

\title{
ĐÁNH GIÁ HÌNH THÁI VÀ CHỨC NĂNG TIM THAI Ở SẢN PHỤ TIỀN SẢN GIẬT TẠI KHOA PHỤ SẢN VÀ VIỆN TIM MẠCH BỆNH VIỆN BẠCH MAI
}

\author{
Nguyễn Phương Thảo1, Phạm Thị Hồng Thi², \\ Phạm Bá $\mathrm{Nha}^{3}$, Nguyễn Thị Duyên ${ }^{1}$
}

\section{TÓM TẮT}

Mục tiêu: Đánh giá được sự thay đổi hình thái chức năng tim thai ở sản phụ tiền sản giật. Đối tượng và phương pháp: Nhóm bênh: 20 sản phụ tiền sản giật $\geq 18$ tuổi có thai từ 28 tuân trở lên, thai tự nhiên, không mắc các bệnh cấp và man tính. Nhóm chứng: 20 sản phụ khỏe manh có tuổi me và tuổi thai tương đương, thai tự nhiên, không mắc các bệnh cấp và mạn tính; Cả hai nhóm đều thực hiện xét nghiệm sàng lọc cơ bản trước sinh bình thường, đến khám và điều tri tai Khoa Phu Sản và Viên Tim mach Bệnh viện Bạch Mai trong thời gian từ 08/2019 đến 8/2020.Tंhực hiện siêu âm tim thai và thu thâp thông tin từ hồ sơ bệnh án tại bênh viện theo mẫu bệnh án nghiên cứu thống nhất. Kết quả và kết luân: Chỉ số tim ngực và bề dày các thành tim của thai nhi ở nhóm sản phu TSG lớn hơn so với nhóm chứng $(p<0,001)$. Chức năng tâm thu của thai nhi ở sản phụ TSG giảm hơn so với của thai nhi ở me bình thường, biểu hiện ở sự giảm chức năng tim toàn bộ - tăng chỉ số Tei thất phải $(0,39 \pm 0,02$ ở sản phụ TSG, 0,36 $\pm 0,05$ ở sản phụ thường, $\mathrm{p}=0,022)$ và tăng chỉ số Tei thất trái $(0,42 \pm 0,02$ ở sản phụ TSG và $0,40 \pm 0,04$ ở sản phu thường, $p=0,025)$, trong khi phân suất co rút cơ thất trái không thay đổi $(32,84 \pm 2,09$ ở sản phụ TSG và $35,02 \pm 5,31$ ở sản phụ thường, $p=0,101$ )

Tư khóa: Tiền sản giật, chức năng tim thai

${ }^{1}$ Bênh viên Vinmec Hạ Long

${ }^{2}$ Viện Tim mạch Việt Nam

${ }^{3}$ Trường Đại họ Y Hà Nội

Chịu trách nhiệm chính: Nguyễn Phương Thảo

Email: bacsiphuongthaonguyen@gmail.com

Ngày nhận bài: 23.10.2020

Ngày phản biện khoa học: 25.11.2020

Ngày duyệt bài: 8.12.2020

\section{SUMMARY}

TO EVALUATE THE CHANGES IN FETAL CARDIAC MORPHOLOGY AND FUNCTION IN PRE-ECLAMPSIA PREGNANT WOMEN AT DEPARTMENT OF OBSTETRICS AND GYNECOLOGY AND VIETNAM NATIONAL HEART INSTITUTE OF BACH MAI HOSPITAL

Objective: To evaluate the changes in fetal cardiac morphology and function in pre-eclampsia pregnant women.Subjects and methods: Forty pregnant women, who have some characteristics: greater than or equal to 18 year olds, have 28 weeks of pregnancy or above, spontaneous pregnancy, not suffer from acute and chronic diseases, basic prenatal screening tests are nomal, come for medical examination and treatment at Department of Obstetrics and Gynecology and Vietnam National Heart Institute of Bach Mai Hospital from August 2019 to August 2020.Results and Conclusions: The fetal diastolic function in pregnant women with preeclampsia, as assessed by the $\mathrm{E} / \mathrm{A}$ ratios and the $E$ '/ $A$ ' ratios of the left and right ventricles, were not different from the fetal diastolic function in normal pregnant women $(p>0.05)$. The fetal systolic function in pregnant women with preeclampsia reduced than the fetal systolic function in normal pregnant women, manifested in a decrease in overall cardiac function: Increased RV Tei index (0.39 \pm 0.02 in pregnant women with preeclampsia, $p=0.022$ ) and increased left ventricular Tei index $(0.42 \pm 0.02$ in pregnant women with preeclampsia, $\mathrm{p}=0.025)$.

Keywords: pre-eclampsia, fetal cardiac function

\section{I. ĐĂT VẤN ĐỀ}

Tiên sản giật là bệnh lý tim mạch- sản khoa phức tạp gây ra tử vong và biến chứng nặng nề 
cho mẹ, thai nhi và trẻ sơ sinh. Tỷ lệ mắc bệnh thay đổi theo từng khu vực trên thế giới. TSG gây những biến chứng nặng cho mẹ: sản giật, rau bong non, rối loạn đông máu, suy gan, suy thận, chảy máu, phù phổi cấp và biến chứng đối với con: thai chậm phát triển, suy thai, sinh non, suy hô hấp sơ sinh, tăng tỉ lệ bệnh và di chứng về thần kinh, vận động, trí tuệ cho sự phát triển của trẻ sau nàyi, 2,3 .

Để hạn chế cũng như tiên lượng được những biến chứng do TSG gây ra đối với mè và con, hiện nay đã có nhiều phương pháp thăm khám đánh giá tình trạng phát triển và sức khỏe của thai nhi ở thai phụ TSG, trong đó siêu âm Doppler thăm dò tuần hoàn tử cung - rauthai là một trong những phương pháp thăm dò không can thiệp có giá trị và đã được đưa vào các khuyến cáo trong thực hành chẩn đoán và điều trịi. Gần đây, siêu âm tim thai là một phương pháp chẩn đoán trước sinh hiệu quả, giúp đánh giá một cách hữu hiệu tình trạng sức khỏe của thai nhi với độ nhạy và độ đặc hiệu cao, ngày càng được áp dụng rộng rãi, không chỉ nhằm đánh giá bất thường cấu trúc mà còn đánh giá rối loạn chức năng tim ở nhiêu mức độ. Siêu âm tim thai đánh giá rối loạn chức năng tim của thai nhi là công cụ chẩn đoán trước sinh giúp cải thiện tiên lượng thông qua việc kiểm soát các yếu tố nguy cơ, nâng cao kết quả điều trị.

Ở Việt Nam, theo kết quả nghiên cứu của Ngô Văn Tài (2001) ${ }^{1}$, tỷ lệ thai phụ tiên sản giật taai Bệnh viện Phụ sản Trung ương là $5 \%$. Song vẫn chưa có nhiều nghiên cứu về đánh giá chức năng tim thai trên nhóm quần thể nguy cơ cao này, nên chúng tôi tiến hành nghiên cứu với mục tiêu đánh giá chức năng tim thai ở thai phụ bị tiền sản giật.

\section{II. ĐỐI TƯợNG VÀ PHƯƠNG PHÁP NGHIÊN CỨU}

1. Đối tượng và địa điểm nghiên cứu: 40 sản phụ $\geq 18$ tuổi có thai 28 tuân, thai tự nhiên, không mắc các bệnh cấp và mạn tính, xét nghiệm sàng lọc cơ bản trước sinh bình thường đến khám và điều trị tại Khoa Phụ Sản và Viện Tim mạch Bệnh viện Bạch Mai trong thời gian từ 08/2019 đến 8/2020. Loại trừ các trường hợp tim thai có các bất thường: Đang bị rối loạn nhịp tim; Xét nghiệm sàng lọc cơ bản có nguy cơ trung bình trở lên; Siêu âm thai khảo sát hình thái học có bất thường; Bị bệnh tim bất thường cấu trúc hoăc thai lưu tại thời điểm nghiên cứu. Được chia làm 2 nhóm nghiên cứu: nhóm bệnh (mẹ tiền sản giật), nhóm chứng (mẹ hoàn toàn khỏe manh)

2. Phương pháp nghiên cứu:Mô tả cắt ngang có nhóm đối chứng

3. Xử lý số liệu:Kiểm định tính chuẩn của số liệu (Skewness - Kurtosis), tỷ lệ phần trăm, phi tham số, T-test, khi bình phương $\left(X^{2}\right)$, Fisher'exact test, hệ số tương quan ( $r$ ), tỉ suất chênh (OR) với $p<0,05$.

4. Đạo đức nghiên cứu:Nghiên cứu được thực hiện đúng theo quy định về đạo đức trong nghiên cứu y học. Tất cả các thông tin thu thập được mã hóa, bảo mật và chỉ phục vụ cho nghiên cứu.

\section{KẾT QUẢ NGHIÊN CứU VÀ BÀN LUẬN}

1. Đặc điểm nhóm sản phụ tiền sản giật trong nghiên cứu:

Bảng 1: Đặc điểm lâm sàng và cận lầm sàng của nhóm nghiên cứu

\begin{tabular}{|c|c|c|c|}
\hline \multirow{2}{*}{$\begin{array}{l}\text { Các thông số } \\
\text { nghiên cứu của mẹ }\end{array}$} & \multicolumn{2}{|c|}{ Trung bình \pm SD } & \multirow[b]{2}{*}{$\mathbf{p}$} \\
\hline & $\begin{array}{l}\text { Nhóm sản phụ } \\
\text { tiên sản giật }(n=20)\end{array}$ & $\begin{array}{c}\text { Nhóm chứng } \\
(n=20)\end{array}$ & \\
\hline \multicolumn{4}{|c|}{ Đặc điểm lâm sàng } \\
\hline Tuối (năm) & $30,55 \pm 4,48$ & $27,80 \pm 5,18$ & 0,0812 \\
\hline BMI trước mang thai $\left(\mathrm{kg} / \mathrm{cm}^{2}\right)$ & $23,14 \pm 0,97$ & $20,11 \pm 2,01$ & $<0,001$ \\
\hline Huyết áp tâm thu (mmHg) & $170,75 \pm 11,95$ & $114,75 \pm 9,80$ & $<0,001$ \\
\hline Huyết áp tâm trương $(\mathrm{mmHg})$ & $95 \pm 4,87$ & $60,75 \pm 8,63$ & $<0,001$ \\
\hline Số lần mang thai (lần) & $2,4 \pm 0,99$ & $1,35 \pm 0,49$ & $<0,001$ \\
\hline Con so, n (\%) & $4(20)$ & $13(65)$ & 0,005 \\
\hline Con rạ, n (\%) & $16(80)$ & $7(35 \%)$ & 0,005 \\
\hline \multicolumn{4}{|c|}{ Đặc điểm cận lâm sàng } \\
\hline Hồng câu (T/L) & $4,15 \pm 0,43$ & $3,90 \pm 0,35$ & 0,051 \\
\hline $\mathrm{Hb}(\mathrm{g} / \mathrm{L})$ & $106,50 \pm 12,64$ & $121 \pm 9,99$ & $<0,001$ \\
\hline Bach cầu ( G/L) & $10,31 \pm 1,67$ & $8,49 \pm 1,20$ & $<0,001$ \\
\hline Tiểu câu (G/L) & $210,90 \pm 37,40$ & $288,45 \pm 95,35$ & 0,002 \\
\hline
\end{tabular}




\begin{tabular}{|c|c|c|c|}
\hline Triglyceride (mmol/L) & $3,39 \pm 0,26$ & $7,84 \pm 23,14$ & 0,395 \\
\hline Cholesterol $(\mathrm{mmol} / \mathrm{L})$ & $6,00 \pm 0,45$ & $5,57 \pm 1,34$ & 0,191 \\
\hline LDL C $(\mathrm{mmol} / \mathrm{L})$ & $3,70 \pm 0,57$ & $3,17 \pm 0,15$ & $<\mathbf{0 , 0 0 1}$ \\
\hline GOT $(\mathrm{U} / \mathrm{L})$ & $44,10 \pm 17,52$ & $27,25 \pm 5,88$ & $<\mathbf{0 , 0 0 1}$ \\
\hline GPT $(\mathrm{U} / \mathrm{L})$ & $39,75 \pm 20,33$ & $24,30 \pm 5,77$ & $<\mathbf{0 , 0 0 1}$ \\
\hline Urea $(\mathrm{mmol} / \mathrm{L})$ & $7,37 \pm 2,42$ & $6,26 \pm 0,01$ & 0,066 \\
\hline Creatinine $(\mu \mathrm{mol} / \mathrm{L})$ & $86,10 \pm 15,85$ & $82,19 \pm 0,22$ & 0,077 \\
\hline Protein toàn phần $(\mathrm{g} / \mathrm{L})$ & $55,50 \pm 4,47$ & $63,05 \pm 2,58$ & $<\mathbf{0 , 0 0 1}$ \\
\hline Albumin $(\mathrm{g} / \mathrm{L})$ & $28,15 \pm 3,35$ & $34,18 \pm 2,35$ & $<\mathbf{0 , 0 0 1}$ \\
\hline Chỉ số RI & $0,66 \pm 0,05$ & $0,52 \pm 0,06$ & $<\mathbf{0 , 0 0 1}$ \\
\hline
\end{tabular}

Nhận xét: Các chỉ số: BMI trước mang thai, số lượng bạch cầu, LDL cholesterol, GOT, GPT cùng với chỉ số RI trên siêu âm Doppler tử cung ở nhóm sản phụ TSG cao hơn nhóm chứng $(p<0,05)$. Trong khi đó chỉ số hemoglobin, tiểu cầu, protein toàn phần, albumin ở nhóm sản phụ TSG thấp hơn nhóm chứng $(p<0,01)$.

2. Hình thái và chức năng tim của thai nhi ở sản phụ tiên sản giật và sản phụ thường Bảng 2: Hình thái tim thai ở nhóm sản phụ tiền sản giật

\begin{tabular}{|c|c|c|c|}
\hline \multirow{2}{*}{$\begin{array}{l}\text { Các thông sốnghiên cứu } \\
\text { của thai nhi }\end{array}$} & \multicolumn{2}{|c|}{ Trung bình \pm SD } & \multirow[b]{2}{*}{$\mathbf{p}$} \\
\hline & $\begin{array}{l}\text { Nhóm sản phụ } \\
\text { tiền sản giật }(n=20)\end{array}$ & $\begin{array}{c}\text { Nhóm chứng } \\
(n=20)\end{array}$ & \\
\hline Cân nặng thai nhi (gram) & $776,45 \pm 37,45$ & $1002,55 \pm 204,67$ & $<0,001$ \\
\hline Tân số tim thai (chu kỳ/phút) & $145,70 \pm 6,39$ & $148,45 \pm 6,57$ & 0,187 \\
\hline Chỉ số tim ngực & $0,35 \pm 0,02$ & $0,29 \pm 0,03$ & $<0,001$ \\
\hline Bề dày thất phải tâm trương $(\mathrm{mm})$ & $3,01 \pm 0,29$ & $2,36 \pm 0,27$ & $<0,001$ \\
\hline Bề dày thất phải tâm thu (mm) & $3,88 \pm 0,55$ & $3,33 \pm 0,28$ & $<0,001$ \\
\hline Bề dày thất trái tâm trương $(\mathrm{mm})$ & $2 \pm 0,29$ & $2,18 \pm 0,22$ & $<0,001$ \\
\hline Bề dày thất trái tâm thu ( & $3,73 \pm 0,58$ & $3,17 \pm 0,25$ & $<0,001$ \\
\hline Bề dày VTL tâm trương (mm) & $3,17 \pm 0,29$ & $2,60 \pm 0,23$ & $<0,001$ \\
\hline Bề dày VLT tâm thu (mm) & $4,09 \pm 0,38$ & $3,61 \pm 0,32$ & $<0,001$ \\
\hline
\end{tabular}

Bảng 4: Chức năng tâm trương của thai nhi

\begin{tabular}{|c|c|c|c|}
\hline \multirow{2}{*}{$\begin{array}{l}\text { Các thông số } \\
\text { nghiên cứu tim thai }\end{array}$} & \multicolumn{2}{|c|}{ Trung bình \pm SD } & \multirow[b]{2}{*}{$\mathbf{p}$} \\
\hline & $\begin{array}{c}\text { Nhóm sản phụ } \\
\text { tiền sản giất }(n=20)\end{array}$ & Nhóm chứng $(n=20)$ & \\
\hline Sóng E van 2 lá (cm/s) & $36,4 \pm 2,14$ & $36,70 \pm 4,13$ & 0,775 \\
\hline Sóng A van 2 lá (cm/s) & $51,50 \pm 4,19$ & $54,00 \pm 4,74$ & 0,085 \\
\hline Tỉ lệ E/A thất trái & $0,71 \pm 0,08$ & $0,68 \pm 0,05$ & 0,118 \\
\hline$E^{\prime}$ của thất trái $(\mathrm{cm} / \mathrm{s})$ & $4,52 \pm 0,48$ & $4,50 \pm 0,32$ & 0,908 \\
\hline $\mathrm{A}^{\prime}$ của thất trái $(\mathrm{cm} / \mathrm{s})$ & $6,31 \pm 0,43$ & $6,51 \pm 0,41$ & 0,144 \\
\hline Tì lê $E^{\prime} / A^{\prime}$ thất trái & $0,72 \pm 0,09$ & $0,69 \pm 0,04$ & 0,217 \\
\hline Sóng E van 3 lá (cm/s) & $41,25 \pm 4,58$ & $41,10 \pm 3,66$ & 0,909 \\
\hline Sóng A van 3 lá $(\mathrm{cm} / \mathrm{s})$ & $55,00 \pm 2,73$ & $56,25 \pm 2,73$ & 0,156 \\
\hline Tỉ lê E/A thất phải & $0,75 \pm 0,09$ & $0,73 \pm 0,05$ & 0,324 \\
\hline Sóng $\mathrm{E}^{\prime}$ của thất phải $(\mathrm{cm} / \mathrm{s})$ & $5,59 \pm 0,52$ & $5,43 \pm 0,50$ & 0,312 \\
\hline Sóng $A^{\prime}$ của thất phải $(\mathrm{cm} / \mathrm{s})$ & $7,69 \pm 0,53$ & $7,45 \pm 0,77$ & 0,261 \\
\hline Tỉ lệ E'/A' thất phải & $0,73 \pm 0,04$ & $0,73 \pm 0,06$ & 0,721 \\
\hline
\end{tabular}

Nhận xét: Không có sự khác biệt khi đánh giá chức năng tâm trương của cả thất trái và thất phải củatim thai ở sản phụ có TSG so với sản phụ khỏe mạnh $(p>0,05)$.

Bảng 5: Chức năng tâm thu của thai nhi

\begin{tabular}{|c|c|c|c|}
\hline \multirow{2}{*}{$\begin{array}{c}\text { Các thông số } \\
\text { nghiên cứu tim thai }\end{array}$} & \multicolumn{2}{|c|}{ Trung bình $\mathbf{\text { SD }}$} & \multirow{2}{*}{ p } \\
\cline { 2 - 4 } & $\begin{array}{c}\text { Nhóm sản phụ } \\
\text { tiên sản giật }(\mathbf{n = 2 0})\end{array}$ & Nhóm chứng $\mathbf{( n = 2 0 )}$ & \\
\hline $\begin{array}{c}\text { Vận tốc tâm thu tại } \\
\text { vòng van 2 lá }(\mathrm{Sm})(\mathrm{cm} / \mathrm{s})\end{array}$ & $3,97 \pm 0,17$ & $3,76 \pm 0,46$ & 0,71 \\
\hline
\end{tabular}


VIETNAM MEDICAL JOURNAL N¹ - JANUARY - 2021

\begin{tabular}{|c|c|c|c|}
\hline $\begin{array}{c}\text { Vận tốc tâm thu tại } \\
\text { vòng van 3 lá }(\mathrm{Sm})(\mathrm{cm} / \mathrm{s})\end{array}$ & $6,10 \pm 0,49$ & $4,91 \pm 0,94$ & $<0,001$ \\
\hline VTI ĐMC $(\mathrm{cm} / \mathrm{s})$ & $11,43 \pm 1,05$ & $7,65 \pm 0,30$ & $<0,001$ \\
\hline VTI ĐMP $(\mathrm{cm} / \mathrm{s})$ & $9,51 \pm 0,60$ & $6,69 \pm 0,19$ & $<0,001$ \\
\hline Phât suất co rút cơ (FS) & $32,84 \pm 2,09$ & $35,02 \pm 5,31$ & 0,101 \\
\hline Chỉ số Tei thất trái & $0,39 \pm 0,02$ & $0,36 \pm 0,05$ & 0,022 \\
\hline Chỉ số Tei thất phải & $0,42 \pm 0,02$ & $0,40 \pm 0,04$ & 0,025 \\
\hline
\end{tabular}

Nhận xét: Vận tốc tâm thu tại vòng van 3 lá (Sm), với VTI ĐMC và VTI ĐMP, cùng với chỉ số Tei thất trái và thất phải ở nhóm sản phụ TSG đều lớn hơn so với nhóm chứng $(p<0,05)$.

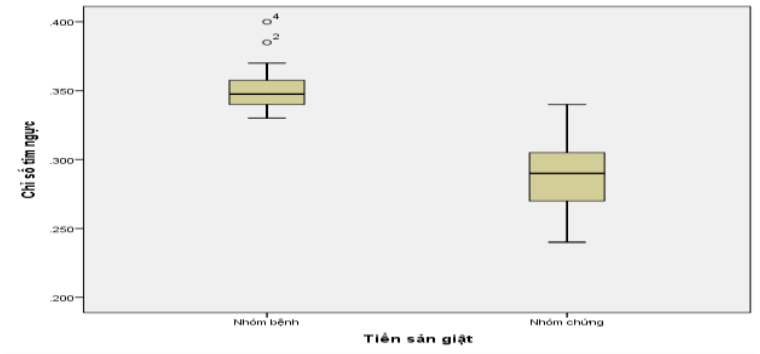

Biểu đồ 1: Chỉ số tim ngực của tim thai nhi trên nhóm sản phụ có tiền sản giật và nhóm sản phukhỏe manh

Nhân xét: Cân nặng thai nhi ở nhóm sản phụ TSG $(776,45 \pm 37,45)$ nhỏ hơn nhóm chứng $(p<0,01)$. Chỉ số tim ngực và bề dày các thành tim của thai nhi ở nhóm sản phụ TSG lớn hơn so với nhóm chứng $(p<0,001)$.
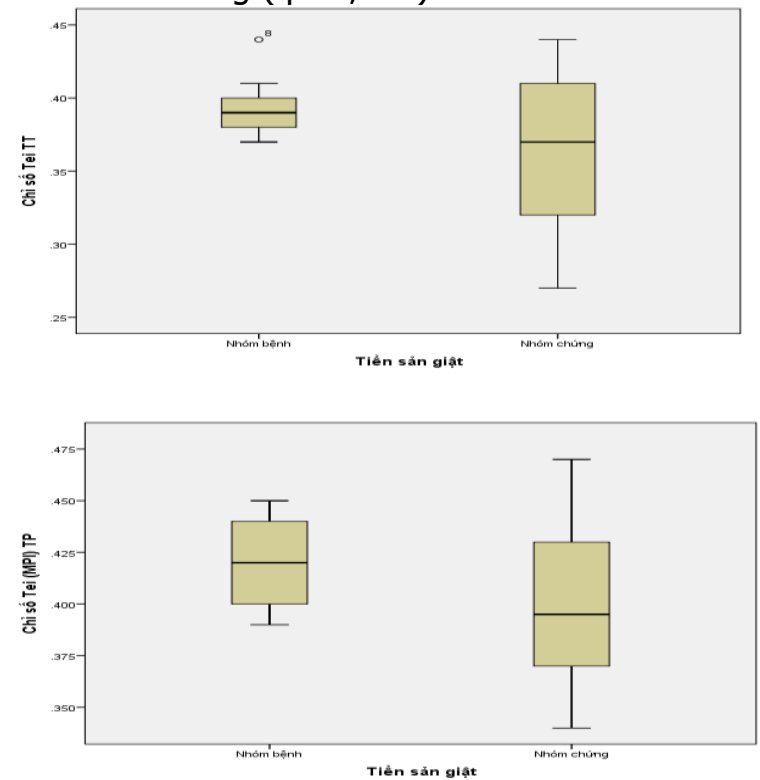

Biểu đồ 2: Chỉ số Tei thất trái và thất phải của tim thai nhi trên nhóm sản phụ có tiền sản giật và nhóm sản phụ không có tiền sản giật

\section{BÀN LUÂ̂N}

Nghiên cứu được tiến hành trên 2 nhóm sản phụ TSG và nhóm chứng là những sản phụ khỏe mạnh với tuổi mẹ và tuổi thai tương đương. Với tính chất khác biệt giữa 2 nhóm, do đó, các biểu hiện lâm sàng, cận lâm sàng có sự khác biệt có ý nghĩa thống kê.

Từ kết quả nghiên cứu, chúng tôi nhận thây sự khác biệt về mặt hình thái giữa tim thai trên sản phụ có TSG so với nhóm chứng. Trong đó, chỉ số tim ngực $(0,35 \pm 0,02)$ cao hơn một cách có ý nghĩa so với nhóm chứng $(0,290 \pm 0,03)$, $p<0,001$. Các chỉ số khác như bề dày vách liên thất, bề dày thất phải tâm trương $(3,02 \pm 0,29)$, bề dày thất phải tâm thu $(3,88 \pm 0,55)$, bề dày thất trái tâm trương $(4,32 \pm 6,31)$, bề dày thất trái tâm thu $(3,73 \pm 0,58)$, bề dày VTL tâm trương $(3,17 \pm 0,29)$, bề dày VLT tâm thu $(4,09$ $\pm 0,38)$ đều lớn hơn nhóm chứng một cách có ý nghĩa thống kê $(p<0,05)$.

TSG làm giảm lượng oxy của thai nhi nhận qua nhau thai. Hậu quả làm tim lớn và dày thành tim cũng như động mạch chủ $(p<0.05)$. Người ta cho rằng con của những thai phụ bị TSG sau này có nhiều khả năng bị bệnh tim hơn. Hơn nữa, theo Narin và $\mathrm{CS}^{5}$, rối loạn chức năng tim và tổn thương cơ tim đã được tìm thấy ở trẻ sơ sinh của các bệnh nhân TSG.

Tuy nhiên, nghiên cứu cho thấy có sự thay đổi chức năng tâm thu do tăng hậu gánh ở thai nhi của những bệnh nhân bị TSG so với nhóm khỏe mạnh. Trong đó, vận tốc tối đa thì tâm thu tại vòng van 3 lá $(\mathrm{Sm})$ của thai nhi ở nhóm TSG cao hơn nhiêu so với ở nhóm khỏe mạnh $(p<0.05)$. Chỉ số VTI ở động mạch chủ $(11,43)$ và VTI ở động mach phổi $(9,51)$ đều cao hơn nhiều so với thai nhi ở nhóm khỏe mạnh $(7,65$ và $6,69)$. Tuy vậy, tần số tim thai của 2 nhóm vẫn tương đương nhau $(p>0,05)$. Như vậy, thông qua các chỉ số VTI và vận tốc tối đa thi tâm thu qua van 2 lá và van 3 lá, cung lượng tim và thể tích nhát bóp ở tim thai ở sản phụ TSG lớn hơn so với nhóm chứng, thể hiên có sự tăng tiền gánh. Nghiên cứu đánh giá chức tim thai ở những phụ nữ TSG nhẹ của Saket Baili và $\mathrm{Cs}^{6}$ năm 2017 cho thấy không có sự khác biệt đáng kể nào được tìm thấy trong các chỉ số của chức năng tâm thu thất giữa hai nhóm. Kết quả này 
khác với nghiên cứu của chúng tôi có lẽ vì đối tượng trong nghiên cứu của chúng tôi đều thuộc nhóm TSG nặng, do đó, sự ảnh hưởng của các yếu tố bệnh lý liên quan đến TSG lên tim thai cũng sẽ lớn hơn, từ đó dẫn tới các biến đổi chức năng tâm thu lớn hơn.

Đối với chức năng tâm trương, chỉ số vận tốc sóng $E$ và sóng $A$, tỷ lệ $E / A$ van 2 lá và van 3 lá của thai nhi có mẹ bị TSG là tương đương nhau $(p>0.05)$. Sóng $E^{\prime}, A^{\prime}$ và tỷ lệ $E^{\prime} / A^{\prime}$ của van nhĩ thất phải và trái ở hai nhóm khác biệt không có ý nghĩa thống kê ( $p>0.05)$. Nghiên cứu của Balli và $\mathrm{CS}^{6} \mathrm{cho}$ thấy rối loạn chức năng tâm trương của tim thai ở thai nhi của những bà me bị TSG nhẹ. Tỷ lệ $E / A$ hai lá và $E / A$ ba lá tương tự nhau ở hai nhóm, nhưng tỷ lệ $E^{\prime} / A^{\prime}$ ở nhóm tiền sản thấp hơn đáng kể so với nhóm khỏe mạnh. Đều này có lẽ do cõ̃ mẫu của chúng tôi còn nhỏ.

Chỉ số Tei (MPI) là một chỉ số kết hợp cả khoảng thời gian tâm thu và tâm trương để thể hiện chức năng tâm thất toàn bộ. Một số nghiên cứu đã ghi nhận rằng MPI không phụ thuộc vào áp lực động mạch, nhịp tim, hình dạng tâm thất, hoặc van nhĩ thất trào ngược hậu gánh và tiên gánh. MPI tăng ở những bệnh nhân có rối loạn chức năng tâm thất. Nghiên cứu cho thấy MPI thất trái và thất phải của thai nhi ở nhóm sản phụ TSG đều cao hơn so với nhóm khỏe manh $(p<0.05)$, đều này cho thấy sự rối loạn chức nằng tim đã bắt đâu có ở những thai nhi có mẹ là TSG.

\section{KẾT LUÂ̂N}

1.Kích thước và bề dày các thành tim của thai nhi ở sản phụ TSG lớn hơn của thai nhi ở sản phụ bình thường. Trong đó chỉ số tim ngực trung bình là $(0,35 \pm 0,02)$, chỉ số bề dày thất phải tâm trương, tâm thulần lượt là $3,01 \pm 0,29$ và $3,88 \pm 0,55$, bề dày thất trái tâm trương và tâm thu lần lượt là $2,92 \pm 0,29$ và $3,73 \pm 0,58$, bề dày VLT tâm trương và tâm thu lần lượt là 3,17 $\pm 0,29$ và $4,09 \pm 0,38$.

2. Chức năng tim toàn bộ của thai nhi ở sản phụ TSG giảm hơn so với của thai nhi ở me bình thường, biểu hiện ở tăng chỉ số Tei thất phải $(0,39 \pm 0,02)$ và tăng chỉ số Tei thất trái $(0,42 \pm$ $0,02)$ trong khi phân suất co rút cơ thất trái vẫn chưa thay đổi $(32,84 \pm 2,09)$.

LờI CẢM ƠN. Chúng tôi xin bày tỏ lòng biết ơn tới Lãnh đạo Bệnh viện Bạch Mai, khoa Phụ Sản, Viện Tim mạch Việt Nam và các phòng, ban của Bệnh viện Bạch Mai đã tạo điều kiện thuận lợi để hoàn thành nghiên cứu.

\section{TÀI LIÊUU THAM KHẢO}

1. Ngố Văn Tài. Một số yếu tố tiên lương trong nhiểm độc thai nghén, Luận án tiến s̃̃ $Y$ học, Trường Đai hoc Y Hà Nối. Published online 2001.

2. Ngô Văn Tài. Tiền sản giật và sản giật. In: Tiền Sản Giật và Sản Giật. 1st ed. Nhà xuất bản Y học; 2006:7-51.

3. Sibai B.M Ramadan K. "Pre-Eclamsia and Eclamsia", Sciarra. Obstet Gynecol , Vol .2, No.7, Pp.1-14.; 1995.

4. sComas M, Crispi F. Assessment of Fetal Cardiac Function Using Tissue Doppler Techniques. FDT. 2012;32(1-2):30-38. doi:10.1159/000335028

5. Narin N, Çetin N, Kıllıç $H$, Başbuğ M, Narin F, Kafalı M, Züm KÜ, Genç $E$, Ustünbaş $H B$. Diagnostic Value of Troponin T in Neonates of Mild Pre-Eclamptic Mothers. NEO. 1999;75(2):137-142. doi: $10.1159 / 000014089$

6. Balli S, Kibar AE, Ece İ, Oflaz MB, Yilmaz 0 . Assessment of Fetal Cardiac Function in Mild Preeclampsia. Pediatr Cardiol. 2013;34(7):16741679. doi:10.1007/s00246-013-0702-8

\section{KẾT QUẢ ĐÎ̂̀U TRI VI PHẪU THUÂTT THOÁT VỊ TUỶ MÀNG TUỶ}

\section{TÓM TẮT}

Nghiên cứu 57 bệnh nhi được chẩn đoán và điều trị thoát vị tuỷ màng tuỷ nhằm mục đích đánh giá kết quả điều trị vi phẫu thuật thoát vị tuỷ -màng tuỳ. Đối tượng và phương pháp nghiến cứu: nghiên cứu mô tả, hồi cứu, cắt ngang. Thời gian và địa điểm

\footnotetext{
${ }^{1}$ Bệnh viện Việt Đức.

Bệnh viện Sản Nhi Thanh Hoá

Chịu trách nhiệm chính: Ngô Mạnh Hùng

Email: ngomanhhung2000@gmail.com

Ngày nhận bài: 22.10.2020

Ngày phản biện khoa học: 24.11.2020

Ngày duyệt bài: 10.12 .2020
}

\section{Ngô Mạnh Hùng ${ }^{1}$, Dư Văn Nam ${ }^{2}$}

nghiên cứu: 1.2018 đến 9.2020 tại bệnh viện Nhi trung ương. Kết quả: tuổi trung bình là $6 \pm 1,3$ (tháng); $89,4 \%$ số bệnh nhân dưới 1 tuổi. Tỉ lệ nữ/nam $=1,15 / 1$. Có $10,5 \%$ số bênh nhân được chẩn đoán trước sinh. Các triệu chứng lâm sàng: tổn thương vận động-cảm giác $(10,5 \%)$; rối loạn cơ tròn $(15,8 \%)$, dãn não thất $(15,8 \%)$. 78,9\% khối thoát vị nằm ở vùng cùng cụt; $96,5 \%$ bệnh nhân có tuỷ bám thấp. Sau mổ, $7 \%$ số trường hợp tuỷ ở vị trí bình thường (so với 3,5\% trước mổ); 78,95\% số bệnh nhân có chất lượng cuộc sống từ mức khá. Kết luần: bệnh lý thoát vị tuỷ-màng tuỷ vẫn còn là một thách thức đối với chuyên ngành.

Tư khoá: thoát vị tuỷ màng tuỷ; tuỷ bám thấp, phẫu thuật. 